\title{
DENTAL MANAGEMENT OF A PATIENT WITH CONGENITAL HYPOTHYROIDISM: A CASE REPORT
}

\author{
Monisha Singhal ${ }^{1}$, Nitin Singh ${ }^{2}$, Rohit Anand ${ }^{3}$, C.P. Chaudhary ${ }^{4}$ \\ ${ }^{1}$ PG Student, Department of Pedodontics and Preventive Dentistry, Chandra Dental College and Hospital, Lucknow, India \\ ${ }^{2}$ Reader, Department of Pedodontics and Preventive Dentistry, Chandra Dental College and Hospital, Lucknow, India \\ ${ }^{3}$ Professor, Department of Pedodontics and Preventive Dentistry, Chandra Dental College and Hospital, Lucknow, India \\ ${ }^{4}$ Professor \& Head, Department of Pedodontics and Preventive Dentistry, Chandra Dental College and Hospital, Lucknow, India
} \begin{abstract}
\begin{tabular}{l|l} 
ABSTRACT \\
Congenital hypothyroidism $(\mathrm{CHT})$ is one of the most common thyroid disorders. It occurs because of \\
dysgenesis of thyroid gland which is responsible for the normal development of neural system. Child patient \\
suffering from congenital hypothyroidism shows various medical and behavioral symptoms which makes \\
routine dental care very challenging to the pediatric dentist. Due to increased awareness and introduction of \\
neonatal screening, the long term hypothyroidism has become rare. The most significant oral conditions \\
related to these patients are delayed eruption and dental caries. The present case report outlines the dental \\
treatment of a 9yr old girl with congenital hypothyroidism.
\end{tabular}
\end{abstract}
Key words: Caries, Congenital Hypothyroidism, Behavior Management

Corresponding Author: Dr. Monisha Singhal

E-mail:

monishasinghal28@gmail.com

Received: $2^{\text {nd }}$ May 2016 Accepted: $15^{\text {th }}$ August 2016 Online: $11^{\text {th }}$ September 2016

\section{INTRODUCTION}

Congenital hypothyroidism is one of the most common thyroid disorders. A recent study in India indicates a prevalence of approximately 1:2630 among people there. It is more prevalent in females (2:1). It occurs because of dysgenesis, dyshormogenesis \& maternal medication with radioiodine, polythiouracil and carbimazole. Thyroid hormones plays very crucial role in the physical and mental system in fetal and postnatal life and its deficiency in infancy causes retardation of growth with physical disability including orofacial complex. ${ }^{1,2}$ In Infants born with congenital hypothyroidism clinical features may not

broad flat nose, poor muscular activity and umblical hernia. The common oral findings in hypothyroidism include the characteristic macroglossia, dysgeusia, delayed eruption, poor periodontal health, altered tooth morphology and delayed wound healing. ${ }^{1,4,5}$

It also exhibits familial tendency. Due to increased awareness and introduction of neonatal screening the long term hypothyroidism has become rare. But neonatal screening is still not available in many countries. ${ }^{6}$ The present case report study outlines the dental treatment of a 9 year old girl with congenital hypothyroidism.

\section{CASE REPORT}

A 9 year old girl (Figure 1) reported to display mild effects that often go unrecognized. ${ }^{3}$ Congenital hypothyroidism is characterized by dwarfism, thick lips, the Department of Pediatric and College Lucknow, U.P, India with her Preventive Dentistry in Chandra Dental 


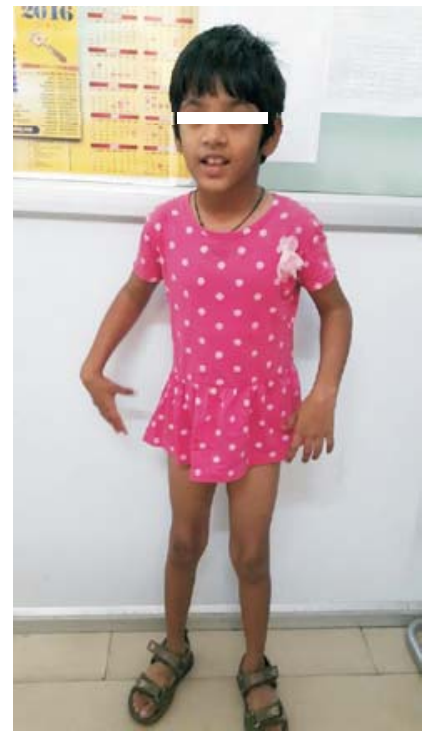

Figure 1

father for the treatment of severe pain and swelling in 75. At the time of reporting, the patient's biometric index record showed weight of $19 \mathrm{~kg}$ and height of 110 $\mathrm{cm}$. She was born of eutocic delivery of a normal evolution pregnancy. The diagnosis of congenital hypothyroidism was made in 5 th month after birth.

The patient was taking thyroxine $75 \mathrm{mcg}$ /day and levocartinine $50 \mu \mathrm{g} / \mathrm{kg} /$ day in divided doses. General physical examination examination revealed short stature, flat nose, dry skin, stubby hands, poor muscle tone and mental retardation. Extraoral examination showed incompetent lips.

Intra oral examination showed large protruding tongue, malocclusion, unilateral posterior cross bite, poor periodontal status, carious $84 \& 85$, root stump of 74 and grossly carious 75 with localized dento-alveolar swelling. Radiographic investigation revealed pulp exposure in 75 with periapical involvement and interradicular bone loss (Figure 2).

The informed consent was obtained from parents and pediatric endocrinologist was consulted. Parent's counseling regarding the treatment plan was done. Treatment was conducted after stimulus hormone test showed the normal values.

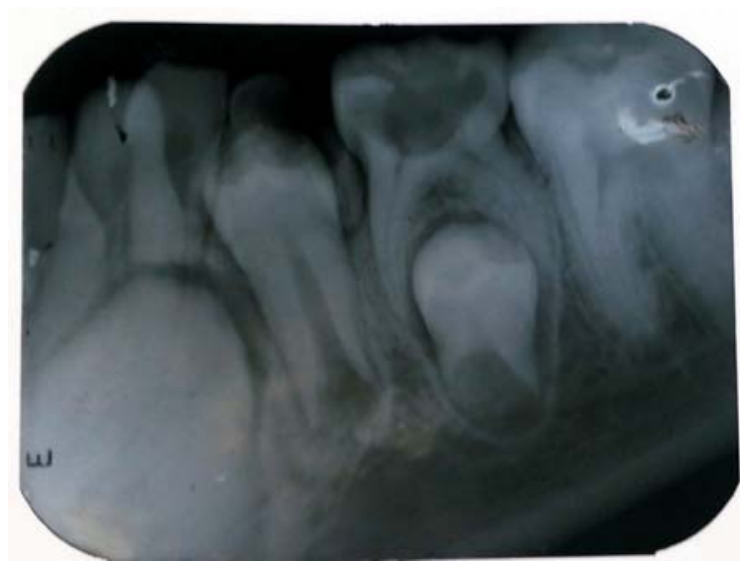

Figure 2

The Oral rehabilitation of patient was planned which included behavior modification, oral hygiene instructions, oral prophylaxis, sealing of carious lesions, endodontic treatment and extraction of root stump. Antibiotics and analgesics were prescribed for severe pain and swelling in 75 and was recalled after 3 days. At the first visit behavior modification was done to attain a cooperative behavior and to instill a positive dental attitude towards treatment followed by oral prophylaxis and oral hygiene instructions. At the second visit restoration of 84,85 with GIC was done and endodontic procedure was started in 75 . In third visit pulpectomy was completed followed by a GIC restoration (Figure.3). In the fourth visit stainless steel crown was placed in relation to 75 (Figure 4, 5). Fluoride application was done and preventive

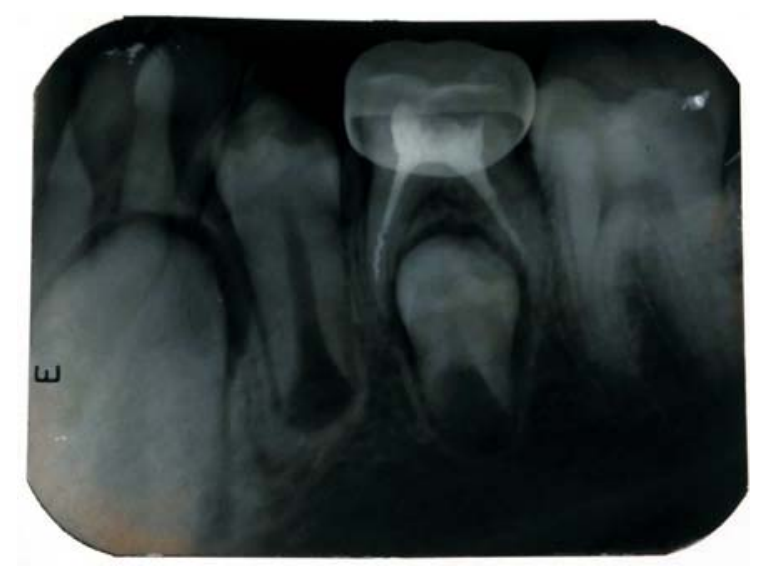

Figure 3 


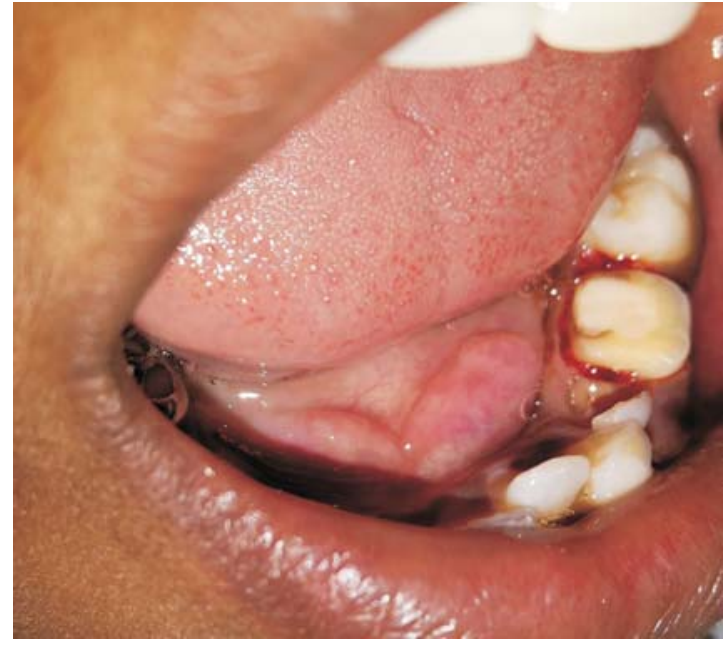

Figure 4

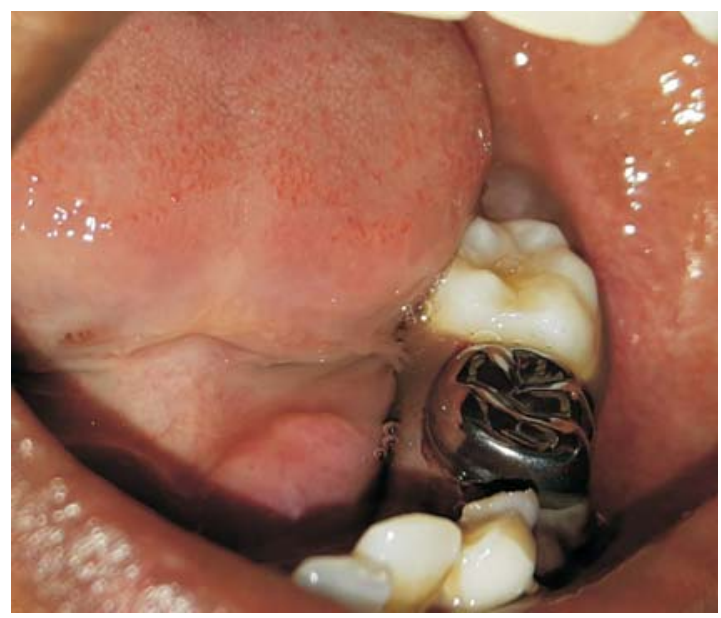

Figure 5

measures were reinforced. Three months post operatives radiograph was taken to evaluate the integrity of the restoration.

\section{DISCUSSION}

Oral manifestations of the congenital anomalies are alteration in morphology of tooth or in chemical composition which are inherited or metabolic disorders which can be detected in $\mathrm{x}$ - ray. ${ }^{7}$ In various scientific literatures the most commonly observed clinical features of hypothyroidism are: retarded physical and mental development, presence of umbilical hernia, change in skin color and hair loss, thick lips and macroglossia. The lack of growth in terms of height is observed at very early stage. ${ }^{8}$ In relation to physical development, it can be noted that child showed lower size and weight percentiles than recommended by WHO (World Health Organization) and CDC (Center for Disease Control and Prevention) (Figure 6)., ${ }^{9,10}$ The most significant oral conditions related to this patient were delayed eruption and dental caries.

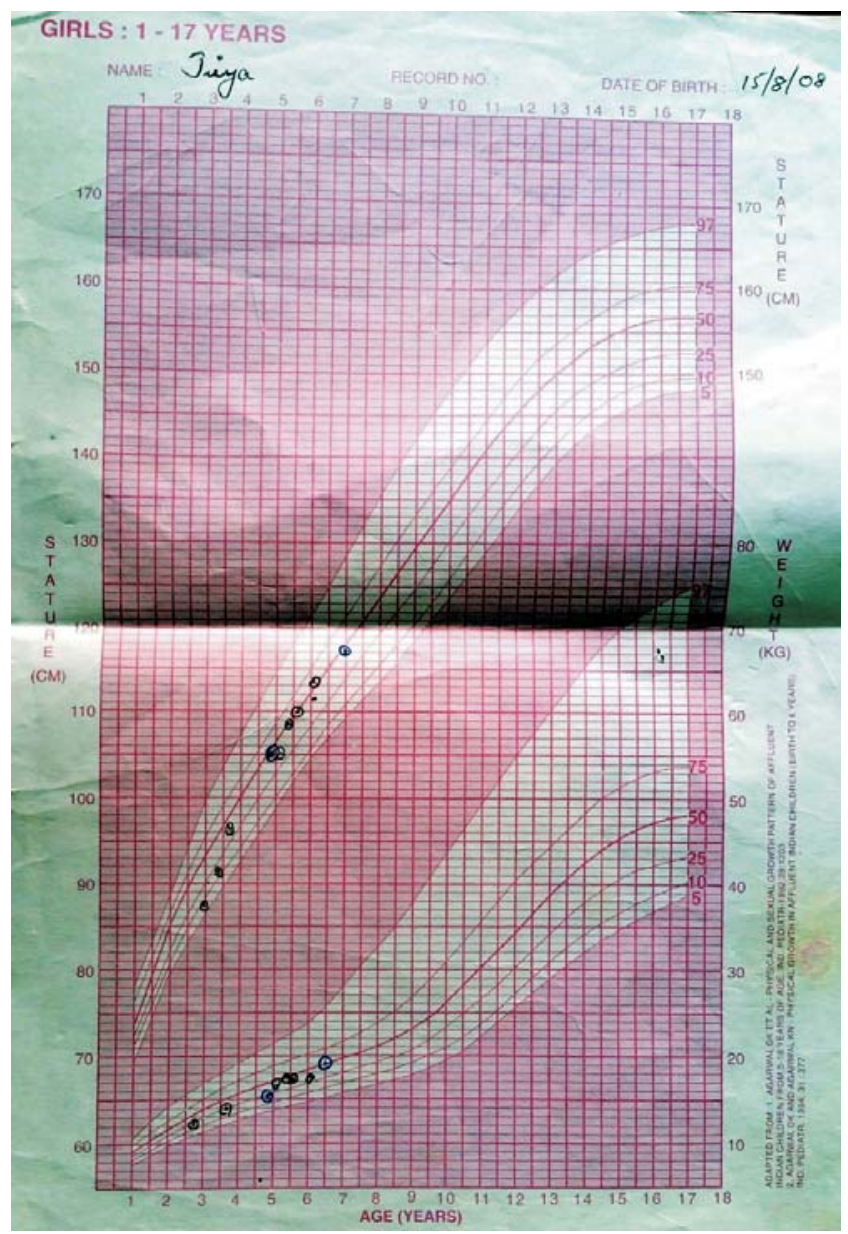

Figure 6

The diagnosis of genetic and metabolic disorders is usually given by endocrinologists and geneticists. But the oral manifestations must be identified by pediatric dentist. Simple dental treatment can considerably enhance the patient's well-being. Congenital hypothyroidism can cause severe mental retardation as well as delay in growth if left untreated..$^{10}$ Early diagnosis and adequate treatment from the first week of 
life results in normal linear growth and intelligence. ${ }^{8}$

A proper medical consultation is very necessary before performing any dental treatment .If the doctor has doubts or concerns after a complete medical and dental evaluation, medical consultation with the patient's pediatrician is warranted before performing any dental treatment. ${ }^{12}$

A thorough knowledge of patient's medical history, drugs and dosage for treatment and any past medical complication of CHT is necessary to evade complications in dental clinic such as hypothyroid coma which includes hypothermia, bradycardia, hypotension and seizures. ${ }^{13}$ In an individual with more intense signs \& symptoms of thyroid hypo function (e.g., mental apathy, drowsiness or slow speech), dental treatment should be postponed until consultation with the patient's primary care physician.

Dentist should assess the level of mental disability by consulting the physician for frequent medical assessment and coordinated care when appropriate. This enhances the level of co-operation, by understanding the communication level of child, activities what child can perform, commands which patient can understand and accept. Moreover caretakers can also help in controlling the unrestrained behavior of the child. The most important factor for providing dental care to these individuals is the knowledge of a dentist and his skills to treat them. ${ }^{14}$

Once the hypothyroid patient is under appropriate medical observation, there are no further complications in the dental treatment except malocclusion and macroglossia if present. ${ }^{15,16}$

As the child grows the problem of delayed eruption become more critical. Therefore, management at an early age rehabilitates the oral function which in turn will promote general as well as oral health.

\section{CONCLUSION}

Early diagnosis and treatment of congenital hypothyroidism reduces systemic complications and developmental anomalies. Pediatric dentist should provide dental treatment smoothly without any systemic complications. Neonatal screening should be performed so as to improve the health and well-being of the individual involved.

\section{REFERENCES}

1. Ayala C, Lemus O \& Frías M. Oral and systemic manifestations of congenital hypothyroidism in children. A case report. J Oral Res 2015; 4(5):329-34.

2. Buket Ayna. Dental Treatment Way of Congenital Hypothyroidism: Case Report. International Dental and Medical Disorders 2008; 1.

3. Desai M P. Disorders of thyroid gland in India. Indian J Pediatr 1997; 64: 11-20

4. Rastogi MV, LaFranchi HS. Congenital hypothyroidism. Orphanet J Rare Dis 2010; 5: 17.

5. Vulsma T, Gons MH, De Vijlder JJ. Maternal-fetal transfer of thyroxine in congenital hypothyroidism due to a total organification defect or thyroid agenesis. N Engl J Med 1989; 321:13-6.

6. Grant DB, Smith I, Fuggle PW, Tokar S, Chapple J. Congenital hypothyroidism detected by neonatal screening: relationship between biochemical severity and early clinical features. Arch Dis Child 1992; 67: 87-90.

7. Witkop CJ. Clinical aspects of dental anomalies. Int Dent J 1976;26:378-390.

8. Suma GN, Lakhanpal M, Dhillon M, Srivastava S. Orofacial manifestations of congenital hypothyroidism: Clinicoradiological case report. J Indian Acad Oral Med Radiol 2014; 26:111-4.

9. Center for Disease Control and Prevention [consultadonoviembre de 2011]. Disponibleen: http://www.cdc.gov/growthcharts.

10. Shaw L, Foster TD. Size and development of the dentition in endocrine deficiency. J Pedod1989; 13:155- 60.

11. Little JW, Falace DA. Dental management of the medically compromised patient. 6 ed. St. Louis: Mosby; 2002:283-303.

12. Lazarus J, Brown R, Daumerie C, Hubalewska-Dydejczyk A, Negro R, Vaidya B. European Thyroid Association guidelines for the management of subclinical hypothyroidism in pregnancy and in children. Eur Thyroid J 2014;3(2):76-94.

13. Amjad H.Wyne. Dental management of mentally retarded patients. Pakistan Oral \& Dent 2002; 22 (1) : 3-8.

14. Reynoso RME. Congenital hypothyrodism and its oral manifestations. Revista Odontológica Mexicana 2014;18(2):133-8.

15. Atas A, Cakmak A, Karazeybek H. Congenital hypothyroidism. J of CourrentPediatr 2007; 5: 70-6. 